\title{
Moisture susceptibility of high and low compaction dry process crumb rubber modified asphalt mixtures
}

\author{
M.M. Rahman ${ }^{1}$, \\ Senior Lecturer \\ School of Architecture, Design and the Built Environment, \\ Nottingham Trent University, Nottingham, NG1 4BU, United Kingdom \\ Phone: $+44(0) 1158486502$, Fax: $+44(0) 1158486140$ \\ E-mail: mujib.rahman@ntu.ac.uk \\ G.D. Airey, \\ Professor \\ Nottingham Transportation Engineering Centre (NTEC), \\ Department of Civil Engineering, \\ The University of Nottingham, Nottingham, NG7 2RD, United Kingdom \\ Phone: +44(0)115951 3913, Fax: +44(0)1159513909 \\ E-mail: gordon.airey@nottingham.ac.uk \\ A.C. Collop \\ Professor \\ Nottingham Transportation Engineering Centre (NTEC), \\ Department of Civil Engineering, \\ The University of Nottingham, Nottingham, NG7 2RD, United Kingdom \\ Phone: +44(0)115951 3935, Fax: +44(0)1159513909 \\ E-mail: andrew.collop@nottingham.ac.uk
}

1. Corresponding author

Submission date: 14/11/2009

Word count: 6732 


\begin{abstract}
The field performance of dry process Crumb Rubber Modified (CRM) asphalt mixtures has been reported to be inconsistent with stripping and premature cracking on the surfacing. One of the concerns is that, as achieving field compaction of CRM material is difficult because of the inherent resilient nature of the rubber particle, non-uniform field compaction may lead to deficient bond between rubber and bitumen. To assess the influence of compaction, a series of CRM and control mixtures were produced and were compacted at two levels; $4 \%$ (low, optimum laboratory compaction), and $8 \%$ (high, field experience) air void content. The long-term durability, in terms of moisture susceptibility of the mixtures was assessed by conducting repeated moisture conditioning cycles. The mechanical properties (stiffness, fatigue, and resistance to permanent deformation) were determined in the Nottingham Asphalt Tester (NAT). The results indicated that compared to conventional mixtures, the CRM mixtures, irrespective of compaction effort, are more susceptible to moisture with the degree of susceptibility primarily depending on the amount of rubber in the mixture, rather than the difference in compaction. This behaviour is different to conventional mixtures where, as expected, poorly compacted mixtures were found to be more susceptible to moisture than well compacted mixtures.
\end{abstract}

Key words: Scrap tyres, crumb rubber, asphalt, moisture susceptibility, stiffness, fatigue, permanent deformation. 


\section{INTRODUCTION}

Scrap tyres form a major part of the world's solid waste management problem. Each year the UK alone produces around 30 million waste tyres with 1 billion being produced globally. Almost half of them are landfilled or stockpiled with the rest being recycled, exported, and disposed of illegally. Since 2006, the EU's Landfill Directive has barred disposal of most tyres as a landfill material. As a result, if alternatives to landfill disposal are not found, disposal costs will increase and illegal dumping or inadequate storage will continue to worsen. The fire risk associated with illegal dumps has the potential to cause significant environmental harm. In addition, road traffic is predicted to increase by $17 \%$ in the UK alone between 2000 and 2010 (DETR 2000) and, consequently, the number of post-consumer tyres arising in UK is likely to increase.

Within the expanding recycling market, only two applications, to date, have shown the potential to use a significant number of scrap tyres, (i) fuel for combustion and (ii) crumb rubber modified (CRM) material for asphalt paving. Although combustion can consume millions of tyres, it is not considered as an ideal environmental solution. This leaves the use of crumb rubber in CRM asphalt mixtures as the only remaining potential market. Over the last two decades, the use of crumb rubber in asphalt paving has gained popularity due to the improved mechanical and functional performance of CRM asphalt mixtures as well as the proficient way of dealing with this waste product (Epps, 1994).

CRM asphalt paving products can be made by several techniques, including a wet process and a dry process. In the wet process, CRM binders are produced when finely ground crumb rubber $(0.075$ to $1.2 \mathrm{~mm})$ is mixed with bitumen at elevated temperatures prior to mixing with the aggregate. Binder modification of this type is due to physical and compositional changes in an interaction process where the rubber particles swell in the bitumen by absorbing a percentage of the lighter fraction of the bitumen, to form a viscous gel. In the dry process, granulated or ground rubber and/or crumb rubber $(0.4$ to $10 \mathrm{~mm})$ is used as a substitute for a small portion of the fine aggregate (typically 1-3 percent by mass of the total aggregate in the mixture). The rubber particles are blended with the aggregate prior to the addition of the bitumen.

Considerable research into the wet process and the production of CRM binders has been undertaken over the last thirty years. The wet process has the advantage that the binder properties are better controlled although it needs special equipment to blend bitumen and rubber. On the other hand, the dry process is a far less popular method due to increased costs for specially graded aggregate to incorporate the reclaimed tyre crumb, construction difficulties and most importantly poor reproducibility and premature failures in terms of cracking and ravelling of the asphalt road surfacing (Emery, 1995, Choubane et al., 1999, Harmelink, 1999, Amirkhanian, 2000, Fager, 2001, Hunt, 2002). However, the dry process has the potential to consume larger quantities of recycled crumb rubber compared to the wet process resulting in greater environmental benefits. In addition, the production of CRM asphalt mixture by means of the dry process is logistically easier than the wet process and, therefore, the dry process is potentially available to a much larger market.

Research into the dry process is limited. The main assumption with the dry process is that rubber crumb is solely part of the aggregate and the reaction between bitumen and crumb rubber is negligible. Research has showed that in the dry process, rubber crumb swells and reacts with bitumen at elevated temperatures and has an effect on the performance of the bitumen and, therefore, the asphalt mixture (Singleton, 2000, Airey et al., 2003). In addition, field trials have shown that the performance of dry process CRM material used as a surface layer to be inconsistent with service life varying from two to twenty years. Several reasons are reported for this variability, such as uncontrollable crumb rubber sources, poor workmanship, the flexible nature of the rubber particles, the adhesion with bitumen, and the reaction described above. Tyre properties change with age and vary from manufacturer to manufacturer and this variability of scrap tyre source makes it even more difficult to control the consistency of the properties of the crumb rubber and consequently the properties of the mixture. Some of the above-mentioned problems could be mitigated by using CRM material as a flexible binder course layer where the direct impact of load is less compared to a surfacing layer. Consequently, in this study, CRM mixtures were designed to modify a typical UK dense graded binder course material. 
One of the primary concerns regarding the performance of the dry process is that achieving field compaction of CRM material is difficult because of the inherent resilient nature of the rubber particles, which may lead to non-uniform compaction and poor bond between rubber and bitumen. This paper investigates the effect of different degrees of compaction on the moisture susceptibility of the CRM mixtures and whether the variability in compaction or the influence of rubber content in the mixture is the dominant factor. In addition, the investigation also looked at whether the influence of rubber-bitumen interaction due to short-term ageing in the loose state has any significantly effect on achieving target compaction and whether the mixture becomes more susceptible to moisture because of this initial interaction. Various mechanical properties, such as stiffness, fatigue, and resistance to permanent deformation, were determined on a range of laboratory prepared specimens. The mechanical properties were determined after different degrees of moisture conditioning on a range of CRM mixtures compacted to achieve $4 \%$ (to simulate optimum compaction in the laboratory) and $8 \%$ target air void contents (to simulate field experience). The results were compared with the similar mixtures tested in their unconditioned state (Airey et al., 2003) and also with control mixtures without any rubber content.

\section{DURABILITY OF DRY PROCESS CRM ASPHALT MIXTURES}

The durability of asphalt mixtures is defined as their ability to resist damage caused by environmental factors (including water, temperature and fuel) in the context of a given amount of traffic for a long period of time without any significant deterioration. Many factors affect the durability of asphalt mixtures but it is generally agreed that the two primary factors are embrittlement of the bitumen through age hardening and damage due to moisture (Scholz and Brown, 1994). Water damage is normally manifested in the loss of adhesion between the aggregate and the bitumen commonly referred to as stripping and/or loss of strength or stiffness of the mixture. Long-term ageing (hardening) is primarily associated with the loss of volatile components and progressive oxidation of the bitumen during in-place service in the field. Ageing causes an increase in viscosity of the bitumen and a consequential stiffening of the mixture, which results in an increase in elastic modulus and embrittlement of the asphalt mixture. Although the increase of elastic modulus can improve the load distribution capacity and permanent deformation resistance by producing a stiffer material, the increase in brittleness as a result of excessive hardening often leads to pavement cracking and loss of durability in terms of water resistance and moisture susceptibility (Vallerga, 1981, Li and Nazarian, 1995). Both ageing and water damage mechanisms result in a reduction of the structural integrity of the mixture and can lead to early asphalt pavement failure.

The influence of both short-term (maximum six hours at $160^{\circ} \mathrm{C}$ in the loose state to simulate the production to laying period) and long-term (five days at $85^{\circ} \mathrm{C}$ of compacted specimens to simulate approximately 10 years in-service condition) ageing on CRM asphalt mixture performance was investigated by Rahman et al. (2006). The results demonstrated that the influence of short-term ageing on the mechanical properties of highly compacted (4\% target air voids) is far greater compared to long-term ageing. In addition, the results also indicated that, irrespective of rubber content in the mixtures, the load spreading ability (stiffness modulus) increased in all mixtures following both short-term and long-term ageing. The two-performance indicators, fatigue and resistance to permanent deformation, marginally improved following short-term ageing of the loss mixtures, but generally deteriorated after long-term ageing of the compacted CRM specimens.

Rahman et al. (2004) also studied the moisture susceptibility of CRM asphalt mixtures and found that highly compacted CRM asphalt mixtures (4\% target air voids) are more susceptible to moisture than conventional mixtures irrespective of rubber content, with significant reduction in stiffness especially for mixtures with $5 \%$ rubber content. However, analysis of the fatigue test data indicated that despite significant reduction in stiffness, CRM mixtures still maintain better fatigue life compared to conventional asphalt mixtures, although resistance to permanent deformation at $60^{\circ} \mathrm{C}$ was found to be marginally inferior. 


\section{MIXTURE DESIGN}

Historically, depending on type and application, dry process CRM asphalt mixtures are manufactured by adding rubber particles at $1 \%$ to $3 \%$ by mass of total mixture with sizes up to $6.3 \mathrm{~mm}$ being used (Heitzman, 1992, Epps, 1994). However, in this investigation, the design of CRM mixtures consisted of replacing $3 \%$ and $5 \%$ of the aggregate fraction with granulated crumb rubber between 2 and $8 \mathrm{~mm}$ in size. For practical purposes, the crumb rubber was grouped into two single size fractions; passing $6.3 \mathrm{~mm}$ and retained on $3.35 \mathrm{~mm}$, and passing $3.35 \mathrm{~mm}$ and retained on $0.3 \mathrm{~mm}$, and added to the Dense Bitumen Macadam (DBM) mixture gradation by substituting for similar sizes of aggregate fraction. As the majority of the granulated crumb rubber was less than $3.35 \mathrm{~mm}$, the two fractions were not replaced in equal amounts but consisting of $20 \%(<6.3 \mathrm{~mm} \&$ $>3.35 \mathrm{~mm})$ and $80 \%(<3.35 \mathrm{~mm} \&>0.3 \mathrm{~mm})$. A $100 / 150$ penetration grade bitumen, as specified in BS EN 12591, was used to produce the CRM asphalt mixtures at a binder content of $5.25 \%$ by mass of total mixture.

The design curve of the continuously graded $20 \mathrm{~mm}$ maximum aggregate size DBM mixture, as specified in BS 4987-1:2001 (specified as AC 20 dense bin 100/150 in EN 13108), was adjusted to incorporate $3 \%$ and $5 \%$ of 2 to $8 \mathrm{~mm}$ crumb rubber. The dense, continuously graded asphalt mixture was chosen to meet the UK design specification for binder course layers. Figure 1 shows the grading envelopes of the mixture and the design gradings that were used in the study.

It is important to note that, as the density of the rubber particles are lower than the aggregate and the CRM asphalt mixtures were initially batched gravimetrically, the volumetric gradations for the control and CRM mixtures will differ. The final gravimetric grading were therefore converted to volumetric gradings to check that they were still within the grading envelope of the $20 \mathrm{~mm}$ DBM asphalt mixture.

A range of control (no rubber) and CRM mixtures were produced with the following variables:

- $\quad$ Crumb rubber content by mass of total aggregate: $0 \%, 3 \%$ and $5 \%$,

- $\quad$ Short-term age conditioning: 0,2 and 6 hours storage in an oven at $155^{\circ} \mathrm{C}$,

- $\quad$ Compaction effort (air void content): $4 \%$ voids to simulate optimum compaction in the laboratory and $8 \%$ voids to simulate field condition.

- $\quad$ Number of specimens in each combination : 12

Sixteen combinations were produced with the control mixtures being produced at two short-term age conditions ( 0 and 6 hours) whereas three short-term conditions ( 0,2 and 6 hours) were used for the production of the CRM mixtures as greater bitumen modification was expected through rubber-bitumen interaction. All specimens were produced by means of gyratory compaction with the following compaction parameters:

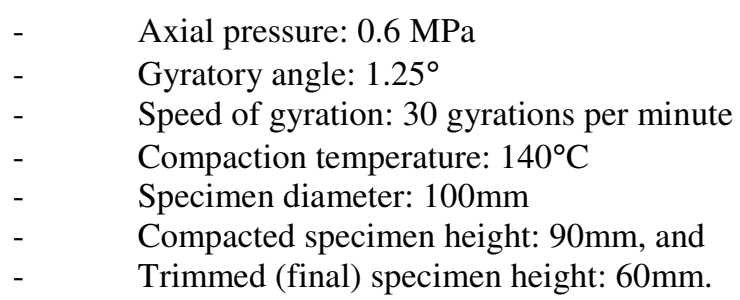

The different materials were coded as follows; crumb rubber content as R0, R3 and R5, short-term conditioning as $\mathrm{C} 0, \mathrm{C} 2$ and $\mathrm{C} 6$, and air void content (compaction effort) as $\mathrm{L}$ for low air void content of $4 \%$ and $\mathrm{H}$ for high air void content of $8 \%$. For example, R3C6H refers to the CRM asphalt mixture with 3\% rubber content by mass, short-term conditioned for 6 hours with an air voids content of $8 \%$. The photographs of some of the specimens are shown in Figure 2. 


\section{EXPERIMENTAL PROGRAMME}

\section{Mechanical Properties}

The mechanical properties were evaluated using the Nottingham Asphalt Tester (NAT) suite of tests. The overall testing programme is shown in Figure 3.

The specifications of the mechanical tests are as follows:

Indirect Tensile Stiffness Modulus (ITSM): The testing was performed according to BS DD213:1993 using the following specifications:

Test temperature: $20^{\circ} \mathrm{C}$,

Loading rise-time: 124 milliseconds, and

Peak transient horizontal deformation: $5 \mu \mathrm{m}$.

Each sample was tested twice by rotating $90^{\circ} \pm 10^{\circ}$ about its horizontal axis with results within $10 \%$ of each other being used for the analysis. During the test, a load pulse is applied along the vertical diameter of a cylindrical specimen and the resultant peak transient deformation measured along the horizontal diameter. The stiffness modulus is then a function of load, deformation, specimen dimensions and an assumed Poisson's ratio of 0.35 .

Indirect Tensile Fatigue Test (ITFT): The ITFT was performed according to BS DD ABF 2002 using the following specifications:

Test temperature: $20^{\circ} \mathrm{C}$,

Loading condition: controlled-stress,

Loading rise-time: 120 milliseconds, and

Failure indication: $9 \mathrm{~mm}$ vertical deformation

The results were interpreted in terms of initial tensile strain versus number of load repetitions to produce $9 \mathrm{~mm}$ vertical deformation. The tensile strain was calculated as:

$\varepsilon_{x \max }=\frac{\sigma_{x \max }}{S_{m i x}}(1+3 v)$

where; $\sigma_{\mathrm{x} \text { max }}$ is the maximum horizontal tensile stress at the centre of the specimen $(\mathrm{kPa}), \varepsilon_{\mathrm{xmax}}$ is the maximum initial horizontal tensile strain at the centre $(\mu \varepsilon)$, and $S_{\text {mix }}$ is the indirect tensile stiffness modulus $(\mathrm{MPa})$

Confined Repeated Load Axial Test (CRLAT): The CRLAT is a modified version of the Repeated Load Axial (RLA) test as specified in DD 226: 1996 (Nunn et al., 1999). The main advantage of using the CRLAT over the RLAT is that the CRLAT includes the influence of aggregate gradation, size and shape in permanent deformation as well as the influence of different binders (Oliver et al, 1996). In addition, different studies (LCPC, 1996, Ulmgren, 1996, Ulmgren et al., 1998, Nunn et al., 1999) have shown that the CRLAT discriminates better between different aggregate gradations over a broad range of asphalt mixtures (porous asphalt, gussasphalt and asphalt concrete).

The tests were conducted using the following test parameters:

Test temperature: $60^{\circ} \mathrm{C}$,

Test duration: 7200 seconds (3600 cycles) with a load pattern 1 second loading on (load application period) followed by one second off (rest period),

Axial stress: $100 \mathrm{kPa}$,

Confining pressure: $70 \mathrm{kPa}$, and

Conditioning stress: $10 \mathrm{kPa}$ for 600 seconds 
All test specimens were subjected to 2 hours conditioning at the test temperature prior to testing. The results were analysed for each individual mixture subjected to moisture conditioning and were compared with corresponding unconditioned test results. It is important to note that slight expansion was observed during the two hours high temperature $\left(60^{\circ} \mathrm{C}\right)$ conditioning prior to permanent deformation testing. As there is no established parameter to use in assessing the response of CRM mixtures in the CRLA test, a comparison of the results was made, using the mean strain rate and total strain as reported by Brown et al. (1995) and Gibb (1996) for asphalt mixtures.

Following the ITSM testing on all specimens, half of the C0 and C6 mixtures were subjected to various moisture conditioning cycles and then seven of them were tested for fatigue using the ITFT and five for permanent deformation using the CRLAT. The R3C2 and R5C2 specimens were not included in the ITFT and CRLAT testing programme as initial trails highlighted that the difference in performance between $\mathrm{C} 0$ and $\mathrm{C} 2$ mixtures was insignificant.

\section{Water Sensitivity Testing Protocol}

Numerous test methods are available to investigate the moistures damage mechanisms of asphalt mixtures, although their success at predicting field performance is variable (Scholz and Brown, 1994, Lottman, 1982, Tunnicliff and Root, 1984, Terrel and Al- Swailmi, 1994). However, it is generally agreed that moisture can reduce the integrity of the asphalt mixture in two ways (Mostafa et al., 2003, Kennedy, 1985), namely; a) failure of the adhesion between the mineral aggregate particles and bitumen films commonly referred to as stripping and b) reduction of the cohesive strength and stiffness of the asphalt mixture.

The procedure for moisture sensitivity testing, which was followed in this investigation, was based on the Link Bitutest testing protocol (Scholz, 1995) for asphalt mixtures. The test method involves determining the ratio of conditioned to unconditioned ITSM values as measured with the NAT. A brief testing procedure is described below:

- The pre-conditioning consists of saturation under a partial vacuum of $510 \mathrm{~mm} \mathrm{Hg}$ at $20^{\circ} \mathrm{C}$ for 30 minutes.

- Percentage saturation is calculated using the following formula:

$$
S=\left[\frac{M_{w}-M_{d}}{\frac{M_{d}}{G_{m b}}-\frac{M_{d}}{G_{m m}}}\right] * 100
$$

Where; $S$ is the percent saturation, $M_{d}$ is the mass of dry specimen $(g), M_{w}$ is the mass of wet specimen $(\mathrm{g}), \mathrm{G}_{\mathrm{mb}}$ is the bulk specific gravity and $\mathrm{G}_{\mathrm{mm}}$ is the maximum specific gravity.

- The samples are then transferred to a preheated water bath at $60^{\circ} \mathrm{C}$ under atmospheric pressure for 6 hours and moved to another water bath at atmospheric pressure at $5^{\circ} \mathrm{C}$ for 16 hours. The samples are finally conditioned under water at $20^{\circ} \mathrm{C}$ (atmospheric pressure) for 2 hours prior to stiffness testing.

- Determine stiffness ratio as follows:

$$
\text { Stiffness ratio }=\frac{\operatorname{ITSM}_{C i}}{\operatorname{ITSM}_{U}} ; i=1,2,3 \ldots
$$

- Above steps are repeated for subsequent cycles.

It is important to note that the test method used in this study to predict the water sensitivity of asphalt mixtures is highly empirical (Scholz, 1995); as a consequence, it falls short of accurately predicting field performance. After each conditioning cycle, the specimens were allowed to dry for a further 2 hours at $20^{\circ} \mathrm{C}$ in a conditioning chamber prior to ITSM testing and the same procedure 
was followed for the subsequent cycles. The number of moisture conditioning cycles was limited to three for control mixtures and due to significant stiffness reduction, two for the CRM mixtures. A photograph of the R5C6L specimen subjected to two moisture-conditioning cycles is presented in Figure 4.

As shown in the figure, it was observed that during partial vacuum conditioning, some rubber particles on the surface were displaced. This was felt not to have a major significance on the moisture conditioning results. However, during six hours moisture conditioning at $60^{\circ} \mathrm{C}, \mathrm{CRM}$ specimens did expand in the vertical direction by approximately 3 to $4 \mathrm{~mm}$ and consequently, they appeared to be relatively fragile with extensive cracking especially in the mixtures with $5 \%$ rubber content.

\section{RESULTS}

\section{Saturation}

The percentage saturation versus voids contents for the control and CRM mixtures are presented in Figure 5. In general, the percentage saturation increases with increasing rubber and void content in the mixtures. In addition, it was observed that rubber particles generally plucked out from the surface of the specimen which formed paths for water to enter into the mixture matrix, consequently increasing the percentage of saturation during partial vacuum water conditioning. The results indicate that the propensity of moisture induced damage for poorly compacted rubbermodified and control mixtures are higher than for the highly compacted control and CRM asphalt mixtures.

\section{Stiffness modulus}

Table 1 presents a summary of the ITSM values of all the high and low compaction asphalt mixtures including the average, maximum, minimum, standard deviation and calculated percentage saturation. The results show that there are considerable variations between minimum and maximum stiffness in both the control and CRM mixtures. The average stiffness values presented in Table 1 were used to calculate the stiffness ratio (ratio of moisture conditioned stiffness to unconditioned stiffness) to investigate the effect of moisture conditioning on the load bearing capacity (stiffness modulus) of the control and CRM asphalt mixtures. The results are then converted to the percentage of stiffness modulus change compared to the unconditioned stiffness at each cycle and presented in Figure 6.

As the CRM mixtures were produced with an extra compaction effort to achieve target density, the rebound effect of rubber particles is greater in the 5\% CRM mixtures due to the extra rubber content. However, based on the test results it appears that the issue of under compaction (high air void content) is less significant for the CRM mixtures than was found for the control mixtures. In addition, the issue of short-term ageing does not appear to have any added benefit or any adverse effect on the stiffness of the CRM mixtures after moisture conditioning as both C0 and C6 mixtures showed a reduction in stiffness.

It can be seen that in the higher void content control mixture there is a fairly uniform reduction of stiffness up to $13 \%$ following three moisture-conditioning cycles. This is probably the direct consequence of intrusion of water into the void space as more saturation was observed during partial vacuum conditioning. For the highly compacted control mixtures, increased stiffness up to $30 \%$ indicates that the mixtures had not been subjected to enough conditioning cycles to induce noticeable moisture damage. On the other hand, irrespective of short-term age conditioning and compaction effort, both the CRM mixtures show a reduction of stiffness with the $3 \%$ CRM mixture being significantly lower than the 5\% CRM mixtures. After two-moisture conditioning cycles, the reduction of stiffness for the highly compacted 3\% CRM mixtures is in the range of $26 \%$ to $31 \%$ against $14 \%$ to $23 \%$ for the poorly compacted mixtures. Compared to the $3 \%$ CRM mixtures, the reduction of stiffness was considerably higher in the corresponding R5 mixtures in both void conditions indicating that increasing rubber content in the mixture would lead to a more moisture susceptible material. 


\section{Fatigue Performance}

The regression lines in terms of initial strain and number of cycles to failure together with coefficients of correlation for all mixtures are presented in Tables 2 and 3. With the exception of mixtures MR5C6L and MR5C6H, the fatigue and strain equations have all been established with a fairly high degree of confidence. The difficulty of obtaining consistent results in the ITSM test after two moisture conditioning cycles may have contributed to the scatter in initial strain calculations, and consequently the lower correlation.

The results show that, in general, at both high and low stress levels the number of cycles to failure is considerably reduced in moisture conditioned mixtures than in their unconditioned state. Although the fatigue lives for the highly compacted and short-term aged control mixture are slightly improved following moisture conditioning, the overall reduction of fatigue lives is significantly higher in all mixtures especially for the R5 mixtures. In addition, irrespective of compaction effort and short-term ageing, fatigue lives for all CRM mixtures are generally poorer than their unconditioned state results. In addition to that, the predicted strain is considerably higher in the moisture conditioned CRM mixtures compared to control mixtures. In terms of predicted fatigue life, with the exception of MR0COL, all the other control mixtures showed relatively similar fatigue performance compared to their unconditioned state. In contrast, five out of eight CRM mixtures showed significant reduction of fatigue life indicating that moisture in general has an adverse effect on the fatigue performance.

Although predicted strain is generally higher in less compacted control mixtures, their relative fatigue performance appears to deteriorate in a similar manner after moisture conditioning. This is despite the increased stiffness modulus following moisture conditioning in the highly compacted control mixtures. On the other hand, the effect of moisture conditioning appears to be similar in both void contents CRM mixtures. However, the reduction of performance is predominantly due to the increased rubber content and variable stiffness of the mixtures rather than the compaction effort.

\section{Permanent Deformation}

The differences in material ranking by means of the two permanent deformation test parameters, total strain and strain rate/cycle, can be attributed to the sensitivity of the total strain parameter to any initial slack in the test apparatus due to the rough top surface of the CRM mixtures (Figure 4) as well as the fundamental differences in what each parameter is measured. For total strain, any delayed elastic response that cannot be recovered during the one-second recovery period will be added to the final strain measurement, while the strain rate parameter is a more direct measurement of the viscous response (permanent strain) of the material. For the highly elastic (rubberised) and less stiff CRM mixtures, the proportion and actual strain magnitude of the delayed elastic component will inevitably be relatively high resulting in an increase in total strain. For this reason, the strain rate parameter can be considered to be a more reliable and accurate means of assessing the permanent deformation performance of the dry process CRM asphalt mixtures. The total strain (\%) and average strain rate (microstrain/cycle) between 1500 and 3000 cycles are presented in Table 4 . It should be reported that some specimens from the 5\% CRM mixtures became very fragile following moisture conditioning that resulted in specimen failure under loading and these results were, therefore, omitted from the comparison.

The results show that compared to the unconditioned state, the resistance to permanent deformation for the continuously graded DBM control mixtures decreases due to the reduction of mixture's cohesion after moisture ageing. Relative to the control mixtures, the replacement of part of the aggregate fractions with crumb rubber results in an increase in permanent strain in both the unaged and moisture conditioned states. In terms of strain rate, relative to control mixture, the resistance to permanent deformation is significantly decreased in CRM mixtures due to moisture conditioning. The increase in strain rate is significantly higher for the R5 mixture than the R3 mixture indicating that the mixture with $5 \%$ crumb rubber content is more susceptible to moistureinduced damage, therefore, potentially less durable in service. 
In addition, although the decrease is slightly lower with increasing voids contents (decreased compaction) in the control mixtures, in general, the effect of moisture conditioning seems to have a similar effect for higher and lower voids content CRM mixtures. Therefore, it can be concluded that although resistance to permanent deformation decreased considerably for the control mixtures as a result of increasing void content (decreased compaction) the relative effect of compaction is considerably lower on the CRM asphalt mixtures.

\section{CONCLUSIONS}

The following conclusions can be drawn from this study:

- Visual inspection showed that plucking of rubber particles from the CRM specimen after moisture conditioning was predominant especially in mixtures with $5 \%$ rubber contents.

- In terms of load bearing capacity (stiffness modulus), CRM mixtures were found more susceptible to moisture induced damage compared to conventional DBM mixtures. The reduction in stiffness was approximately $30 \%$ for mixtures with $3 \%$ crumb rubber and as high as $70 \%$ for $5 \%$ CRM mixtures after only one moisture conditioning cycle. Similar conclusions were drawn from previous laboratory based studies that asphalt rubber mixtures might be more moisture sensitive than conventional dense graded mixtures (Satnawi et al., 1995).

- The influence of short-term oven ageing and compaction effort was found to be less significant in both CRM mixtures, as changes in stiffness are mostly dominated by the rubber content of the mixture.

- The fatigue results indicated that moisture conditioning adversely affected the performance of the CRM mixtures with reductions in fatigue life compared to the corresponding unconditioned state. The reductions in overall fatigue performance of the CRM mixtures subjected to moisture conditioning were mainly due to the reduction in stiffness and extensive cracking. In general, the compaction effort did not appear to have any more significance on the CRM mixtures than it had on the control asphalt mixtures.

- The resistance to permanent deformation of the control and CRM mixtures showed that both mean and total strain were not suitable for CRM mixtures because of the rough top surface, highly elastic nature of the rubber particles and low stiffness of CRM mixtures causing initial densification. Consequently, strain rate was used as it provides a more accurate way to assess the viscous response (permanent deformation) of the asphalt mixtures in the steady state portion of the deformation curve. Significant reductions in permanent deformation resistance were observed for all CRM mixtures following moisture conditioning and long-term ageing. The effect of rubber content was found to be the dominant factor in the permanent deformation resistance, where an increase in rubber content in the mixtures reduced the overall rutting resistance. In addition, short-term ageing and compaction effort had more influence on the rutting performance of control mixtures, whereas, no significant difference was observed in both high and low void content CRM asphalt mixtures. 


\section{REFERNCES}

Airey, G.D., M.M. Rahman, and A.C. Collop. Absorption of Bitumen into Crumb Rubber Using the Basket Drainage Method. International Journal of Pavement Engineering, Vol. 4, No. 2, 2003, pp 105-119.

Airey, G.D., A.C. Collop, and M.M. Rahman. Mechanical Properties of Crumb Rubber Modified Asphalt Mixtures. $3^{\text {rd }}$ Eurasphalt \& Eurobitume Congress, Vienna, Vol. 1, 2004, pp 800-812.

Amirkhanian, S.N. Utilization of Crumb Rubber in Asphaltic Concrete Mixtures-South Carolina Experience. South Carolina Department of Transportation, South Carolina, USA, 2001.

Bahia, H.U. and R. Davis. Effect of Crumb Rubber Modifiers (CRM) on Performance Related Properties of Asphalt Binders. Journal of the Association of Asphalt Paving Technologists, Vol. 63, 1994, pp. 414-449.

Method for Determination of the Indirect Tensile Stiffness Modulus of Bituminous Mixtures- DD 213. British Standards Institution, BSI, London, 1993.

Method for Assessment of Resistance to Permanent Deformation of Bitumen Aggregate Mixtures Subject to Unconfined Uniaxial Loading - DD 185. British Standards Institution, BSI, London, 1994.

Method for the Determination of the Fatigue Characteristics of Bituminous Mixtures Using Indirect Tensile Fatigue Test. British Standard Draft for Development DD ABF, 2002.

Brown, S.F., and T.V Scholz. Development of Laboratory Protocols for the Ageing of Asphalt Mixtures. $2^{\text {nd }}$ Euroasphalt \& Eurobitume Congress, Session 1: Performance Testing and Specification for Binders and Mixtures, Barcelona, September 2000, pp. 83-90.

Choubane, B., G.A. Sholar, J. A Musselman, and G.C.Page. Ten-year Performance Evaluation of Asphalt-Rubber Surface Mixes. In Transportation Research Record: Journal of the Transportation Research Board, No. 1681, Transportation Research Board of the National Academies, Washington, D.C., 1999, pp. 10-18.

Cooper, K.E. and S.F. Brown. Developments of a Simple Apparatus for the Measurement of the Mechanical Properties of Asphalt Mixes. Proceedings of the Eurobitume Symposium, Madrid, 1989, pp. 494-498.

Emery, J. Evaluation of Rubber Modified Asphalt Demonstration Projects. In Transportation Research Record: Journal of the Transportation Research Board, No. 1515, Transportation Research Board of the National Academies, Washington, D.C, 1995, pp 37-46.

Epps, J.A. Uses of Recycled Rubber Tires in Highways. NCHRP Synthesis of Highway Practice 198. Transportation Research Board, National Research Council, Washington D.C., 1994.

Fager, G.A. Asphalt Rubber: A Summary of the Use of Crumb Rubber in the Hot Mixes: Kansas Experience 1990-2000. Kansas Department of Transportation, Kansas, October, 2001.

Gowda, G.V., K.D. Hall, and R.P. Elliott. Arkansas Experience with Crumb Rubber Modified Mixes Using Marshall and Strategic Highway Research Program Level I Design Methods. In Transportation Research Record: Journal of the Transportation Research Board, No. 1530, Washington, D.C., 1996, pp. 25-33.

Harvey S.A and M.T. Curtis. Evaluation of "PlusRide" (A Rubber Modified Plant Mixed Bituminous Surface Mixture). Minnesota Department of Transportation in cooperation with the Federal Highway Administration, St. Paul, Minnesota, 1990.

Hermelink, D. Using Ground Tire Rubber in Hot Mix Asphalt Pavements. Final Report, No. CDOT-DTD-R-99-9, Colorado Department of Transportation, 1999

Hird, A.B., P.J.Griffiths, R.A.Smith. Tyre waste and resource management: A mass balance approach, Viridis Report VR2, Transport Research Laboratory (TRL), Crowthorne, UK, 2002.

Heitzman, M. Design and Construction of Asphalt Paving Materials with Crumb Rubber Modifier. In Transportation Research Record: Journal of the Transportation Research Board, No. 1339, Transportation Research Board of the National Academies, Washington, D.C., 1992, pp. 1-8.

Hunt, E.A. Crumb Rubber Modified Asphalt Concrete in Oregon, Final report SPR 355, Oregon Department of Transportation, 2002.

Kim, S., S.W.Loh, H. Zhai, H. Bahia. Advanced Characterization of Crumb Rubber-Modified Asphalts, Using Protocols Developed for Complex Binder, In Transportation Research Record: Journal of the Transportation Research Board, No. 1767, Transportation Research Board of the National Academies, Washington, D.C., 2001, pp. 15-24.

Mostafa, A., A.A. Halim, and Y. Hassan, (2003). Laboratory Testing of Moisture Susceptibility of Asphalt Concrete, $3^{\text {rd }}$ International Symposium on Maintenance and Rehabilitation of 
Pavements and Technological Control, The University of Minho, Guimaraes, Portugal, July 7-10.

McQuillen, J.L., H.B. Takallou, R.G. Hicks, and D.C. Esch. Economic Analysis of Rubber-Modified Asphalt Mixes, Journal of Transportation Engineering, Vol. 114, 1988, pp. 259-277.

Oliver, J.W.H. Rutting and Fatigue Properties of Crumb Rubber Hot Mix Asphalts. Asphalt Rubber 2000, Vilamoura, Portugal, 2000, pp 221-240.

Rahman, M.M., G.D. Airey, and A.C Collop. Laboratory Investigation to Assess Moisture Sensitivity of Dry Process CRM Asphalt Mixtures. International Conference on Sustainable Waste Management and Recycling: Used / Post-Consumer Tyres, London, 2004, pp 151-162.

Rahman, M.M., G.D. Airey, and A.C Collop. The Influence of Ageing on Dry Process Crumb Rubber Modified Asphalt Mixtures. The International Journal of Pavement Engineering and Asphalt Technology, Vol. 7, No. 1, 2006, pp 10-26.

Shatnawi, M.S., M.Nagarajaiah, and J.Harvey. Moisture Sensitivity Evaluation of BinderAggregate Mixtures. In Transportation Research Record: Journal of the Transportation Research Board, No. 1492, Transportation Research Board of the National Academies, Washington, D.c., 1995, pp. 71-84.

Singleton, T.M., G.D. Airey, and A.C. Collop. Effect of Rubber-Bitumen Interaction on the Mechanical Durability of Impact Absorbing Asphalt, $2^{\text {nd }}$ Eurasphalt and Eurobitume Congress, Vol. 4, Barcelona, 2000, pp. 1053-1060.

Scholz, T.V. Durability of Paving Mixtures. PhD Thesis, School of Civil Engineering, The University of Nottingham, October 1995.

Takallou, H.B., R.G. Hicks, and D.C. Esch. Effect of Mix Ingredients on the Behaviour of RubberModified Asphalt Mixtures. In Transportation Research Record: Journal of the Transportation Research Board, No. 1096, Transportation Research Board of the National Academies, Washington, D.C., 1986, pp. 68-80.

Vallerga, B.A. Pavement Deficiencies Related to Asphalt Durability. Journal of Association of Asphalt Paving Technologists, Vol.50, 1981, pp. 481-491.

Way. G.B. OGFC meets CRM: Where the Rubber Meets the Rubber. Proceedings of the Asphalt Rubber 2000 Conference, Vilamoura, Portugal, 2000, pp 15-32.

William, H. D, I.I. Negulescu. Characterisation of Asphalt Cements Modified with Crumb Rubber from Discarded Tires. In Transportation Research Record: Journal of the Transportation Research Board, No. 1583, Transportation Research Board of the National Academies, Washington, D.C., 1997, pp 37-44. 


\section{$\underline{\text { List of Figures }}$}

FIGURE 1: 20mm DBM aggregate gradation

FIGURE 2: 20mm DBM control and CRM mixtures

FIGURE 3: Flow chart of experimental programme

FIGURE 4: R5C6L specimen after 2 moisture conditioning cycles

FIGURE 5: Percentage saturation of R0, R3, and R5 mixtures

FIGURE 6: Percentage of stiffness change for (a) highly and (b) poorly compacted control and CRM mixtures due to moisture conditioning

\section{$\underline{\text { List of Tables }}$}

TABLE 1: Stiffness modulus following water sensitivity test for mixtures with target voids of $4 \%$ and $8 \%$

TABLE 2: Fatigue equations for highly compacted mixtures

TABLE 3: Fatigue equations for poorly compacted mixtures

TABLE 4: Permanent deformation properties 


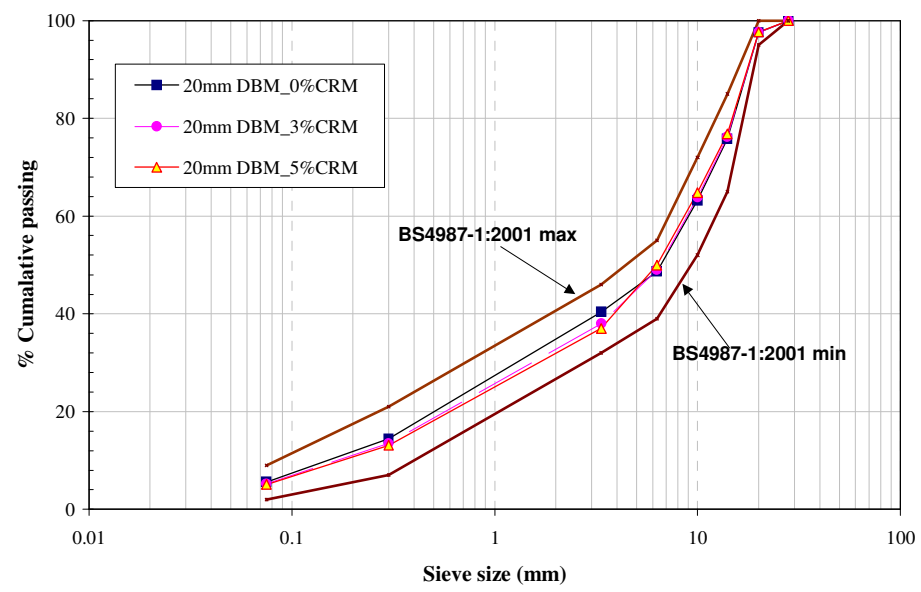

FIGURE 1: 20mm DBM aggregate gradation 


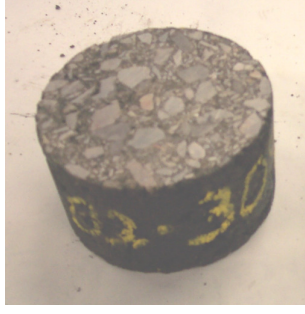

a: $\mathrm{R0}-\mathrm{CO}$

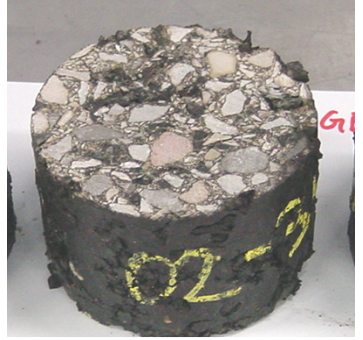

b: R3-C0

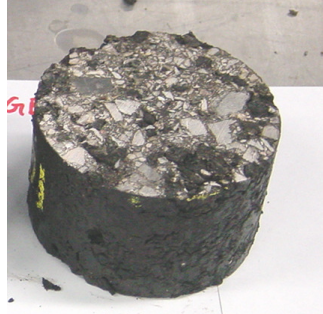

c: R5-C0

FIGURE 2: 20mm DBM control and CRM mixtures 


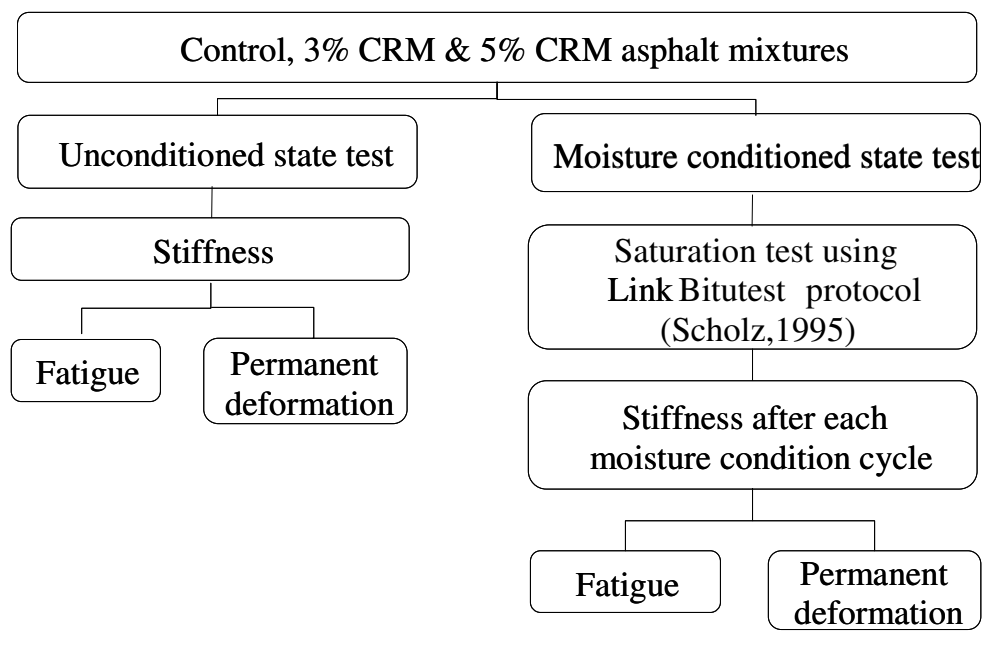

FIGURE 3: Flow chart of experimental programme 


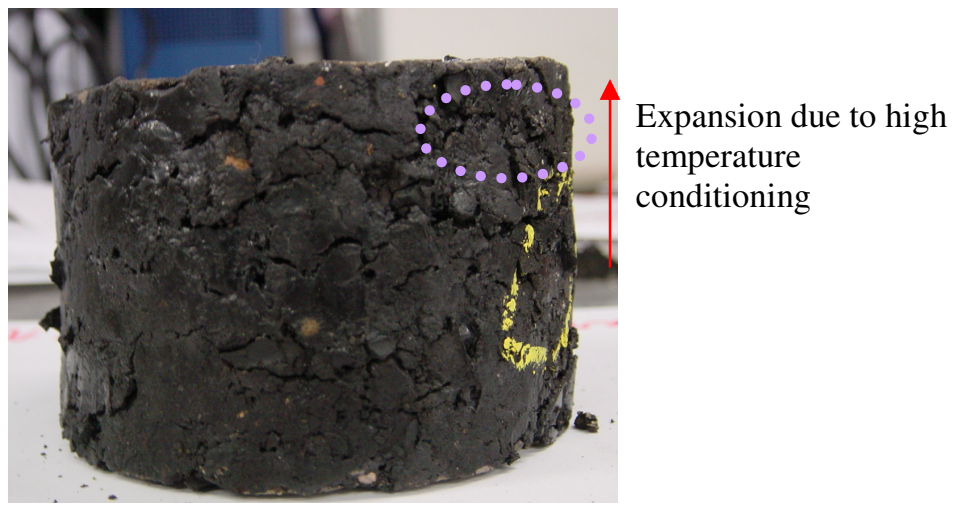

FIGURE 4: R5C6L specimen after 2 moisture conditioning cycles 


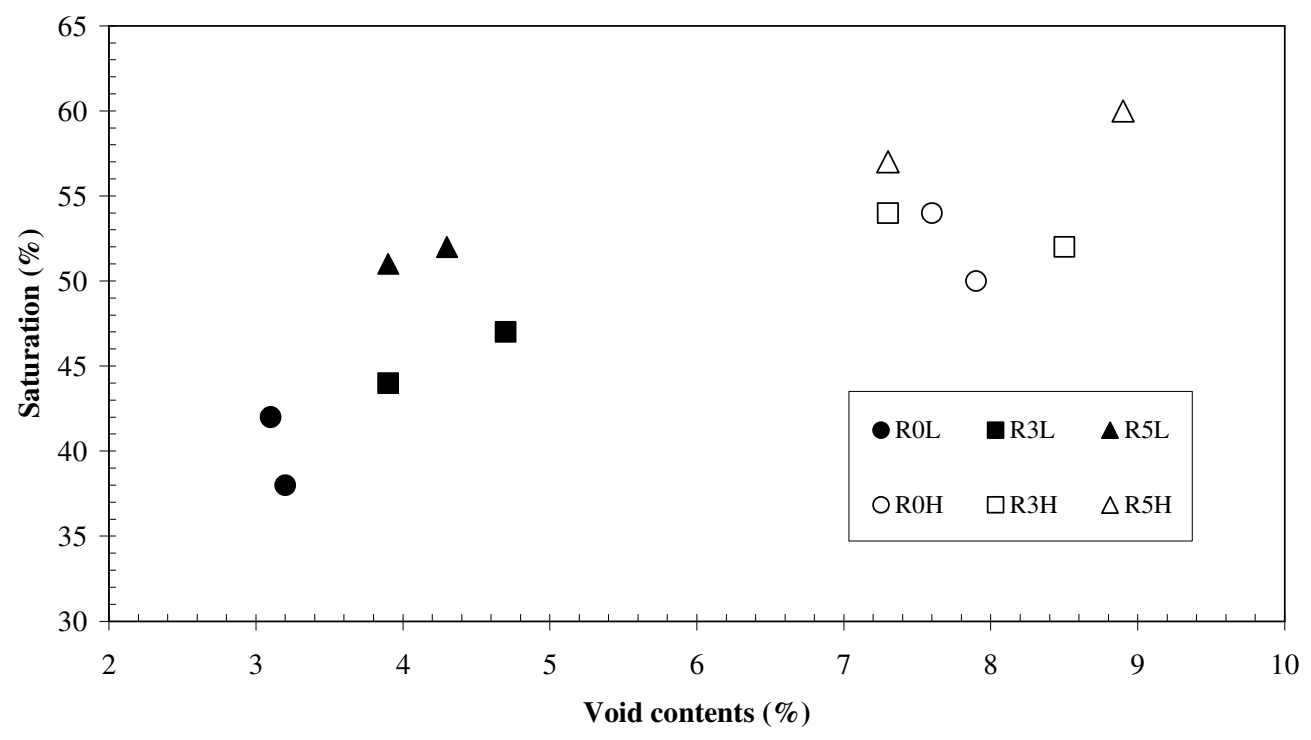

FIGURE 5: Percentage saturation of $R 0, R 3$, and $R 5$ mixtures 
(a)

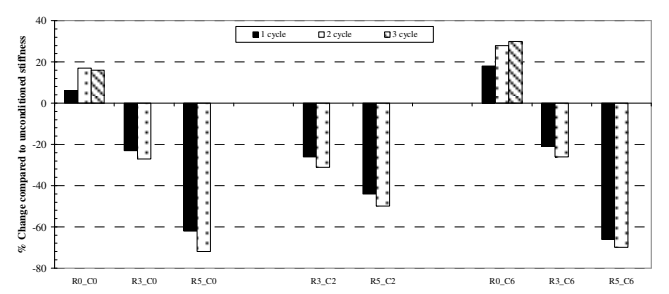

(b)

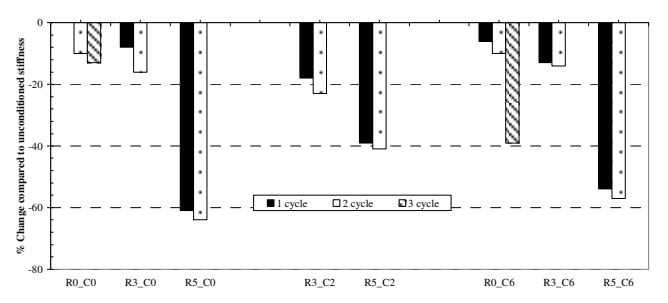

FIGURE 6: Percentage of stiffness change for (a) highly and (b) poorly compacted control and CRM mixtures due to moisture conditioning 
TABLE 2: Stiffness modulus following water sensitivity test for mixtures with target voids of $4 \%$ and $8 \%$

\begin{tabular}{|c|c|c|c|c|c|c|}
\hline \multirow{2}{*}{ Mixture } & \multirow{2}{*}{$\begin{array}{c}\text { Voids (\%) } \\
\text { avg } \\
(\max , \min , s t d)\end{array}$} & \multirow{2}{*}{$\begin{array}{c}\text { Unconditioned } \\
\text { stiffness (MPa) } \\
\text { avg } \\
(\text { max, min, std) }\end{array}$} & \multirow{2}{*}{ ه } & \multicolumn{3}{|c|}{ Conditioned stiffness (MPa) } \\
\hline & & & & $\begin{array}{c}\mathbf{1}^{\text {st }} \text { cycle } \\
\text { avg } \\
(\max , \text { min, std })\end{array}$ & $\begin{array}{c}\mathbf{2}^{\text {nd }} \text { cycle } \\
\text { avg } \\
(\max , \text { min, std })\end{array}$ & $\begin{array}{c}\mathbf{3}^{\text {rd }} \text { cycle } \\
\text { avg } \\
(\max , \text { min, std })\end{array}$ \\
\hline $\mathrm{ROCOL}$ & $\begin{array}{c}\mathbf{3 . 2} \\
4.0,2.4,0.5 \\
\end{array}$ & $\begin{array}{c}\mathbf{3 5 3 6} \\
3646,3360,82 \\
\end{array}$ & 38 & $\begin{array}{c}\mathbf{3 7 5 0} \\
3907,3575,107\end{array}$ & $\begin{array}{c}\mathbf{4 1 3 6} \\
4433,3640,224\end{array}$ & $\begin{array}{c}\mathbf{4 1 1 7} \\
4785,3267,364\end{array}$ \\
\hline R0C6L & $\begin{array}{c}\mathbf{3 . 1} \\
3.8,2.2,0.5\end{array}$ & $\begin{array}{c}\mathbf{4 3 3 4} \\
4873,3627,395\end{array}$ & 42 & $\begin{array}{c}\mathbf{5 1 1 9} \\
5696,4532,293\end{array}$ & $\begin{array}{c}\mathbf{5 5 3 6} \\
5832,5040,224\end{array}$ & $\begin{array}{c}\mathbf{5 6 1 7} \\
6285,4767,364\end{array}$ \\
\hline $\mathrm{R} 3 \mathrm{COL}$ & $\begin{array}{c}\mathbf{3 . 9} \\
5.9,2.1,1.0\end{array}$ & $\begin{array}{c}\mathbf{2 7 5 3} \\
3159,2527,190\end{array}$ & 44 & $\begin{array}{c}\mathbf{2 1 3 1} \\
2396,1843,147\end{array}$ & $\begin{array}{c}\mathbf{2 0 0 5} \\
2232,1666,179\end{array}$ & \multirow{6}{*}{ Not done } \\
\hline $\mathrm{R} 3 \mathrm{C} 2 \mathrm{~L}$ & $\begin{array}{c}\mathbf{3 . 5} \\
5.4,2.2,0.9 \\
\end{array}$ & $\begin{array}{c}\mathbf{3 0 8 4} \\
3349,2825,173 \\
\end{array}$ & 46 & $\begin{array}{c}\mathbf{2 2 9 4} \\
2500,2022,175 \\
\end{array}$ & $\begin{array}{c}\mathbf{2 1 2 2} \\
2448,1968,165 \\
\end{array}$ & \\
\hline R3C6L & $\begin{array}{c}\mathbf{4 . 7} \\
5.6,3.1,0.7\end{array}$ & $\begin{array}{c}\mathbf{3 4 2 1} \\
3782,3100,211\end{array}$ & 47 & $\begin{array}{c}\mathbf{2 7 0 9} \\
3127,1759,393\end{array}$ & $\begin{array}{c}\mathbf{2 5 3 8} \\
2881,1783,385\end{array}$ & \\
\hline $\mathrm{R} 5 \mathrm{C} 0 \mathrm{~L}$ & $\begin{array}{c}\mathbf{4 . 3} \\
6.0,2.3,1.5 \\
\end{array}$ & $\begin{array}{c}\mathbf{1 9 8 4} \\
2198,1723,181\end{array}$ & 52 & $\begin{array}{c}\mathbf{7 6 0} \\
1142,649,189\end{array}$ & $\begin{array}{c}\mathbf{5 4 9} \\
812,422,144\end{array}$ & \\
\hline R5C2L & $\begin{array}{c}\mathbf{4 . 4} \\
5.7,2.4,1.6\end{array}$ & $\begin{array}{c}\mathbf{2 1 6 5} \\
2932,1632,555\end{array}$ & 54 & $\begin{array}{c}\mathbf{1 2 1 3} \\
1812,793,359\end{array}$ & $\begin{array}{c}\mathbf{1 0 8 4} \\
1713,727,357\end{array}$ & \\
\hline R5C6L & $\begin{array}{c}\mathbf{3 . 9} \\
5.5,3.0,0.6 \\
\end{array}$ & $\begin{array}{c}3398 \\
4050,2810,335 \\
\end{array}$ & 51 & $\begin{array}{c}\mathbf{1 1 5 5} \\
1905,732,430\end{array}$ & $\begin{array}{c}\mathbf{8 8 5} \\
1378,644,228 \\
\end{array}$ & \\
\hline $\mathrm{ROCOH}$ & $\begin{array}{c}\mathbf{7 . 6} \\
8.2,6.6,0.5\end{array}$ & $\begin{array}{c}\mathbf{2 2 1 6} \\
2768,1908,299\end{array}$ & 54 & $\begin{array}{c}\mathbf{2 2 1 5} \\
2522,1949,179\end{array}$ & $\begin{array}{c}\mathbf{1 9 8 6} \\
2274,1761,169\end{array}$ & $\begin{array}{c}\mathbf{1 9 2 0} \\
2215,1666,179\end{array}$ \\
\hline $\mathrm{R} 0 \mathrm{C} 6 \mathrm{H}$ & $\begin{array}{c}\mathbf{7 . 9} \\
8.4,7.4,0.2 \\
\end{array}$ & $\begin{array}{c}\mathbf{3 9 2 8} \\
4411,3516,310\end{array}$ & 50 & $\begin{array}{c}\mathbf{3 6 9 1} \\
4126,3315,281 \\
\end{array}$ & $\begin{array}{c}\mathbf{3 5 3 5} \\
3822,3095,233\end{array}$ & $\begin{array}{c}\mathbf{2 3 8 6} \\
3817,2851,346\end{array}$ \\
\hline $\mathrm{R} 3 \mathrm{COH}$ & $\begin{array}{c}\mathbf{7 . 3} \\
8.2,6.2,0.8 \\
\end{array}$ & $\begin{array}{c}\mathbf{2 1 5 4} \\
2286,1911,121 \\
\end{array}$ & 54 & $\begin{array}{c}\mathbf{1 9 7 9} \\
2127,1741,131 \\
\end{array}$ & $\begin{array}{c}\mathbf{1 8 1 9} \\
1942,1702,90 \\
\end{array}$ & \multirow{6}{*}{ Not done } \\
\hline $\mathrm{R} 3 \mathrm{C} 2 \mathrm{H}$ & $\begin{array}{c}\mathbf{8 . 3} \\
9.9,6.5,1.1\end{array}$ & $\begin{array}{c}\mathbf{2 6 5 7} \\
3261,2232,333\end{array}$ & 55 & $\begin{array}{c}\mathbf{2 1 6 8} \\
2537,1826,223\end{array}$ & $\begin{array}{c}\mathbf{2 0 5 3} \\
2414,1774,224\end{array}$ & \\
\hline $\mathrm{R} 3 \mathrm{C} 6 \mathrm{H}$ & $\begin{array}{c}\mathbf{8 . 5} \\
10.3,6.5,1.1\end{array}$ & $\begin{array}{c}\mathbf{2 6 6 4} \\
2965,2456,183\end{array}$ & 52 & $\begin{array}{c}\mathbf{2 3 3 0} \\
2661,2039,173\end{array}$ & $\begin{array}{c}\mathbf{2 3 0 3} \\
2560,2007,174\end{array}$ & \\
\hline $\mathrm{R} 5 \mathrm{COH}$ & $\begin{array}{c}\mathbf{8 . 9} \\
9.9,7.2,0.8\end{array}$ & $\begin{array}{c}\mathbf{1 4 6 7} \\
1820,1101,241\end{array}$ & 60 & $\begin{array}{c}\mathbf{5 7 0} \\
805,462,107\end{array}$ & $\begin{array}{c}\mathbf{5 2 9} \\
826,421,122\end{array}$ & \\
\hline $\mathrm{R} 5 \mathrm{C} 2 \mathrm{H}$ & $\begin{array}{c}\mathbf{7 . 8} \\
10.4,6.1,1.5\end{array}$ & $\begin{array}{c}\mathbf{1 6 5 5} \\
1929,1860,1724\end{array}$ & 59 & $\begin{array}{c}\mathbf{1 0 0 7} \\
1127,914,83\end{array}$ & $\begin{array}{c}\mathbf{9 7 8} \\
1142,884,102\end{array}$ & \\
\hline $\mathrm{R} 5 \mathrm{C} 6 \mathrm{H}$ & $\begin{array}{c}\mathbf{7 . 3} \\
9.2,6.3,1\end{array}$ & $\begin{array}{c}\mathbf{2 6 4 2} \\
3110,2166,308\end{array}$ & 57 & $\begin{array}{c}\mathbf{1 2 2 5} \\
1518,875,224 \\
\end{array}$ & $\begin{array}{c}\mathbf{1 1 4 2} \\
1305,901,156\end{array}$ & \\
\hline
\end{tabular}


TABLE 2: Fatigue equations for highly compacted mixtures

\begin{tabular}{|l|l|l|c||}
\hline Mixture & Fatigue equation & Strain equation & $\mathbf{R}^{\mathbf{2}}$ \\
\hline UR0C0L & $\mathrm{N}_{\mathrm{f}}=1.57 \times 10^{11} \varepsilon^{-3.45}$ & $\varepsilon=1534 \times \mathrm{N} \mathrm{N}_{\mathrm{f}}^{-0.27}$ & 0.94 \\
\hline MR0C0L & $\mathrm{N}_{\mathrm{f}}=2.0 \times 10^{11} \varepsilon^{-3.70}$ & $\varepsilon=918 \times \mathrm{xN}_{\mathrm{f}}^{-0.25}$ & 0.91 \\
\hline UR0C6L & $\mathrm{N}_{\mathrm{f}}=1.02 \times 10^{12} \varepsilon^{-3.541}$ & $\varepsilon=1879 \times \mathrm{N}_{\mathrm{f}}^{-0.255}$ & 0.90 \\
\hline MR0C6L & $\mathrm{N}_{\mathrm{f}}=8.0 \times 10^{13} \varepsilon^{-4.41}$ & $\varepsilon=1167 \times \mathrm{xN}_{\mathrm{f}}^{-0.20}$ & 0.89 \\
\hline UR3C0L & $\mathrm{N}_{\mathrm{f}}=4.80 \times 10^{16} \varepsilon^{-5.416}$ & $\varepsilon=887 \times \mathrm{N}_{\mathrm{f}}^{-0.150}$ & 0.81 \\
\hline MR3C0L & $\mathrm{N}_{\mathrm{f}}=1.0 \times 10^{9} \varepsilon^{-2.24}$ & $\varepsilon=2033 \times \mathrm{N}_{\mathrm{f}}^{-0.38}$ & 0.99 \\
\hline UR3C6L & $\mathrm{N}_{\mathrm{f}}=8.97 \times 10^{19} \varepsilon^{-7.237}$ & $\varepsilon=563 \times \mathrm{N}_{\mathrm{f}}^{-0.136}$ & 0.99 \\
\hline MR3C6L & $\mathrm{N}_{\mathrm{f}}=2.0 \times 10^{14} \varepsilon^{-4.41}$ & $\varepsilon=1614 \times \mathrm{xN}_{\mathrm{f}}^{-0.20}$ & 0.82 \\
\hline UR5C0L & $\mathrm{N}_{\mathrm{f}}=1.02 \times 10^{15} \varepsilon^{-4.694}$ & $\varepsilon=858 \times \mathrm{N}_{\mathrm{f}}^{-0.134}$ & 0.63 \\
\hline MR5C0L & $\mathrm{N}_{\mathrm{f}}=1.0 \times 10^{9} \varepsilon^{-2.24}$ & $\varepsilon=7353 \times \mathrm{N}_{\mathrm{f}}^{-0.38}$ & 0.86 \\
\hline R5C6L & $\mathrm{N}_{\mathrm{f}}=9.03 \times 10^{14} \varepsilon^{-4.779}$ & $\varepsilon=1284 \times \mathrm{N}_{\mathrm{f}}^{-0.204}$ & 0.98 \\
\hline MR5C6L & $\mathrm{N}_{\mathrm{f}}=8.0 \times 10^{8} \varepsilon^{-2.40}$ & $\varepsilon=1787 \times \mathrm{xN}_{\mathrm{f}}^{-0.20}$ & 0.49 \\
\hline
\end{tabular}


TABLE 3: Fatigue equations for poorly compacted mixtures

\begin{tabular}{|l|l|l|c|}
\hline \hline Mixture & Fatigue equation & Strain equation & $\mathbf{R}^{2}$ \\
\hline UR0C0H & $\mathrm{N}_{\mathrm{f}}=1.06 \times 10^{12} \varepsilon^{-3.691}$ & $\varepsilon=1587 \times \mathrm{N}_{\mathrm{f}}^{-0.252}$ & 0.93 \\
\hline MR0C0H & $\mathrm{N}_{\mathrm{f}}=2.0 \times 10^{12} \varepsilon^{-3.68}$ & $\varepsilon=1865 \mathrm{xN}_{\mathrm{f}}^{-0.25}$ & 0.92 \\
\hline UR0C6H & $\mathrm{N}_{\mathrm{f}}=1.87 \times 10^{12} \varepsilon^{-3.879}$ & $\varepsilon=1096 \times \mathrm{N}_{\mathrm{f}}^{-0.220}$ & 0.85 \\
\hline MR0C6H & $\mathrm{N}_{\mathrm{f}}=9.0 \times 10^{12} \varepsilon^{-4.16}$ & $\varepsilon=1217 \mathrm{xN}_{\mathrm{f}}^{-0.23}$ & 0.97 \\
\hline UR3C0H & $\mathrm{N}_{\mathrm{f}}=1.58 \times 10^{13} \varepsilon^{-3.875}$ & $\varepsilon=2336 \times \mathrm{N}_{\mathrm{f}}^{-0.248}$ & 0.96 \\
\hline MR3C0H & $\mathrm{N}_{\mathrm{f}}=6.0 \times 10^{12} \varepsilon^{-3.68}$ & $\varepsilon=1011 \mathrm{xN}_{\mathrm{f}}^{-.25}$ & 0.73 \\
\hline UR3C6H & $\mathrm{N}_{\mathrm{f}}=3.58 \times 10^{11} \varepsilon^{-3.229}$ & $\varepsilon=1564 \times \mathrm{N}_{\mathrm{f}}^{-0.215}$ & 0.69 \\
\hline MR3C6H & $\mathrm{N}_{\mathrm{f}}=2.0 \times 10^{16} \varepsilon^{-4.15}$ & $\varepsilon=1483 \times \mathrm{xN}_{\mathrm{f}}^{-0.22}$ & 0.93 \\
\hline UR5C0H & $\mathrm{N}_{\mathrm{f}}=5.45 \times 10^{14} \varepsilon^{-4.576}$ & $\varepsilon=1277 \times \mathrm{N}_{\mathrm{f}}^{-0.175}$ & 0.80 \\
\hline MR5C0H & $\mathrm{N}_{\mathrm{f}}=9.0 \times 10^{11} \varepsilon^{-3.36}$ & $\varepsilon=2580 \mathrm{xN}_{\mathrm{f}}^{-0.23}$ & 0.77 \\
\hline UR5C6H & $\mathrm{N}_{\mathrm{f}}=2.52 \times 10^{14} \varepsilon^{-4.483}$ & $\varepsilon=1349 \times \mathrm{N}_{\mathrm{f}}^{-0.198}$ & 0.89 \\
\hline MR5C6H & $\mathrm{N}_{\mathrm{f}}=7.0 \times 10^{10} \varepsilon^{-2.81}$ & $\varepsilon=2652 \times \mathrm{xN}_{\mathrm{f}}^{-0.22}$ & 0.63 \\
\hline
\end{tabular}


TABLE 4: Permanent deformation properties

\begin{tabular}{|l|c|c|c|c|c|c|c|c||}
\hline \multirow{3}{*}{ Mixture } & \multicolumn{3}{|c|}{ Strain rate $(\boldsymbol{\mu} \boldsymbol{\varepsilon}$ /cycle) } & \multicolumn{3}{c||}{ Total strain (\%) } \\
\cline { 2 - 10 } & \multicolumn{2}{|c|}{ Unconditioned } & \multicolumn{2}{c|}{ Moisture } & \multicolumn{2}{c||}{ Unconditioned } & \multicolumn{2}{c||}{ Moisture } \\
\cline { 2 - 10 } & avg & std & avg & std & avg & std & avg & std \\
\hline R0C0L & 0.61 & 0.33 & 1.1 & 0.5 & 0.76 & 0.34 & 1.54 & 0.7 \\
\hline R3C0L & 2.09 & 0.78 & 4.8 & 1 & 4.65 & 0.68 & 4.42 & 0.1 \\
\hline R5C0L & 1.27 & 0.24 & 8.6 & 3.7 & 4.6 & 1.05 & 12.11 & 1.2 \\
\hline R0C6L & 0.23 & 0.14 & 0.8 & 0.2 & 0.4 & 0.25 & 1.34 & 0.2 \\
\hline R3C6L & 3.86 & 1.77 & 4 & 1 & 3.75 & 0.58 & 5.68 & 0.3 \\
\hline R5C6L & 1.75 & 1.25 & 6 & 1 & 4.74 & 1.37 & 10.58 & 3.1 \\
\hline \hline R0C0H & 3.84 & 1.08 & 4.5 & 0.5 & 3.16 & 0.66 & 3.34 & 0.4 \\
\hline R3C0H & 2.93 & 0.98 & 7 & 1.1 & 3.54 & 0.52 & 6.97 & 0.5 \\
\hline R5C0H & 3.81 & 1.35 & 7.1 & 2.6 & 6 & 0.59 & 12.27 & 1 \\
\hline R0C6H & 2.61 & 1.21 & 1.6 & 0.8 & 2.67 & 0.55 & 1.53 & 0.4 \\
\hline R3C6H & 3.05 & 1.7 & 5.3 & 2.8 & 4.32 & 0.19 & 7.28 & 0.3 \\
\hline R5C6H & 1.85 & 0.37 & 4.1 & 1.1 & 5.63 & 0.92 & 8.87 & 0.8 \\
\hline
\end{tabular}

